\title{
Postnatal Development of NR2A and NR2B mRNA Expression in Rat Auditory Cortex and Thalamus
}

\author{
Candace Y. Hsieh, ${ }^{1}$ Yiling Chen, ${ }^{2}$ Frances M. Leslie, ${ }^{2,3}$ and Raju Metherate ${ }^{1}$ \\ ${ }^{1}$ Department of Neurobiology and Behavior, University of California, Irvine, Irvine, CA 92697, USA \\ ${ }^{2}$ Department of Pharmacology, University of California, Irvine, Irvine, CA 92697, USA \\ ${ }^{3}$ Department of Anatomy and Neurobiology, University of California, Irvine, Irvine, CA 92697, USA
}

Received: 5 November 2001; Accepted: 2 February 2002; Online publication: 9 April 2002

\section{ABSTRACT}

Sensory cortex in the rat undergoes rapid postnatal development, especially following the onset of sensory function during so-called "critical periods." To investigate potential mechanisms in the auditory forebrain involving different NMDA receptor subunits, we have used in situ hybridization to determine expression patterns of NR2A and NR2B mRNA at postnatal days $4,10,13,18,25$, and adult. In auditory cortex, NR2A mRNA expression is initially weak but increases rapidly over $\sim 2$ weeks. NR2B mRNA levels are initially high and remain high. For both subunits, expression tends to be highest in superficial layers of the cortex (except layer 1). Expression is weaker in the auditory thalamus (medial geniculate). Initially, NR2A mRNA expression is very low, whereas NR2B mRNA expression is moderate; both levels increase over $\sim 2$ weeks. Among medial geniculate subdivisions, NR2A mRNA expression occurs preferentially in the medial division, whereas NR2B mRNA expression is strongest in the ventral division. For auditory cortex and thalamus, NR2A and NR2B mRNA expression peaks about 1 week after the onset of hearing before declining slightly into adulthood. The heterogeneous distribution of NMDAR subunit mRNA throughout development may play a role in auditory forebrain development and function.

Correspondence to: Raju Metherate, Ph.D. - Department of Neurobiology and Behavior - University of California, Irvine 2205 Biological Sciences II - Irvine, CA 92697-4550. Telephone: (949) 824-6141; fax: (949) 824-2447; email: rmethera@uci.edu
Keywords: NMDA receptor, mRNA, development, auditory cortex, medial geniculate, rat

\section{INTRODUCTION}

Postnatal development of sensory cortex is often associated with "critical periods" of heightened sensitivity to sensory experience. Although the mechanisms underlying such periods are not well understood, numerous studies have implied a central role for $N$-methyl-D-aspartate receptors (NMDARs) (for reviews, see Fox et al. 1999; Berardi et al. 2000). Insight into the nature of NMDAR involvement is provided by the observation that changes in the kinetics of NMDAR-mediated excitatory postsynaptic currents (EPSCs) during critical periods are associated with changes in the efficacy of synaptic plasticity (Carmignoto and Vicini 1992; Roberts and Ramoa 1999; Philpot et al. 2001, but see Barth and Malenka 2001). Since NMDAR subunits determine EPSC kinetics (Monyer et al. 1994; Flint et al. 1997; Vicini et al. 1998), it has been hypothesized that changes in NMDAR subunit composition, especially those involving NR2A and NR2B subunits, may determine the time course of critical periods (Nase et al. 1999; Quinlan et al. 1999; Roberts and Ramoa 1999; Cao et al. 2000a, 2000b).

In rat auditory cortex (ACx), the first three postnatal weeks is a time of rapid development of neural circuitry. Thalamic afferents innervate the cortex and its six-layer structure is established early in the first week (Robertson et al. 1991; Ignacio et al. 1995). Rats 
begin to hear on postnatal day (P) 9, cortical responses to acoustic stimuli appear on $\sim \mathrm{P} 10$, and the cortical evoked potential develops rapidly over the next 10 days (Crowley and Hepp-Reymond 1966; Iwasa and Potsic 1982; Blatchley et al. 1987). Physiological studies have shown that glutamate-mediated excitatory postsynaptic potentials (EPSPs) in ACx are initially of small amplitude and long duration but rapidly become larger and faster (shorter latencies to peak and shorter durations) (Aramakis et al. 2000). Neuronal intrinsic membrane properties also change rapidly during this period (Metherate and Aramakis 1999). Thus, as in other sensory cortices, this is a time of rapid change during which the development of neural circuitry may be particularly sensitive to external influences, i.e., a potential critical period (Miao et al. 1998; Aramakis et al. 2000).

To better understand how changes in NMDAR function may contribute to ACx development, we have determined the distribution of NR2A and NR2B subunit mRNA in primary ACx and the auditory thalamus (medial geniculate, MG). We have focused on the first postnatal weeks to identify changes that potentially could regulate an ACx critical period. Knowing the normal distribution of NMDARs will enable future studies of experience-dependent mechanisms in ACx development.

\section{MATERIALS AND METHODS}

\section{Tissue preparation}

All procedures followed the University of California, Irvine, animal use regulations and are similar to those published previously (Winzer-Serhan et al. 1999). Data were obtained from 26 Sprague-Dawley rats, including 13 saline-injected rats from an unrelated study (no difference between the two groups; ANOVA, $p>0.05)$. Rats were decapitated at P4, P10, P13, $\mathrm{P} 18, \mathrm{P} 25$, and adult $(n=4-6$ at each age except $\mathrm{P} 4, n$ $=2$ ), and their brains quickly removed and frozen in isopentane $\left(-25^{\circ} \mathrm{C}\right)$ for $<30 \mathrm{~s}$. Brains were wrapped in airtight bags and stored at $-80^{\circ} \mathrm{C}$ until use $(\leq 2$ months). Serial sections $(20 \mu \mathrm{m})$ containing ACx and MG were cryostat cut $\left(-17\right.$ to $\left.-24^{\circ} \mathrm{C}\right)$ into 5 sets (NR2A antisense, NR2A sense, NR2B antisense, NR2B sense, and Nissl) and thaw-mounted onto slides coated with poly-L-lysine. Sections were fixed in $4 \%$ paraformaldehyde in $0.1 \mathrm{M}$ phosphate-buffered saline (PBS) ( $\mathrm{pH} \mathrm{7.4)} \mathrm{for} 1 \mathrm{~h}$ at room temperature before being rinsed in $0.1 \mathrm{M} \mathrm{PBS}$, air-dried, boxed with desiccant, and stored at $-20^{\circ} \mathrm{C}$.

\section{Plasmid preparation and probe synthesis}

cDNAs encoding full length NMDAR 2A [NR2A; pNR2A 251, 6369 base pair insert in pBS-SK(+) vec- tor, accession No. AF 001423] and NMDAR 2B [NR2B; pJS2B, 5259 base pair insert in pBS-SK $(+)$ vector, accession No. U 11419] subunits were obtained from Dr. S. F. Heinemann (Salk Institute, La Jolla, CA). To generate probes of optimal penetration and specificity, short sequences were cut from the $3^{\prime}$ untranslated region of each cDNA and ligated into the pBS-SK(+) plasmid vector. For NR2A, a 282 base pair sequence (5280-5562) was cut with EcoRV and NheI, whereas for NR2B, a 319 base pair sequence (4935-5254) was cut with BamHI and EcoRI. After ligation and plasmid preparation, cRNA probes in both sense and antisense orientations were synthesized using $\left[{ }^{35} \mathrm{~S}\right]$-labeled UTP and T3 and T7 polymerases (Simmons et al. 1989).

\section{In situ hybridization}

Tissue sections were pretreated with proteinase $\mathrm{K}(0.5$ $\mu \mathrm{g} / \mathrm{mL}$ ) for $10 \mathrm{~min}$ at room temperature (RT), acetylated, dehydrated, and air-dried. Slides were then incubated with $100 \mu \mathrm{L}$ hybridization solution [ $50 \%$ formamide, $10 \%$ dextran sulfate, $0.02 \%$ Ficoll, $0.02 \%$ polyvinyl pyrolidone, $0.02 \%$ bovine serum albumin, $500 \mu \mathrm{g} / \mathrm{mL}$ tRNA, $10 \mathrm{mM}$ dithiothreitol (DTT), $0.3 \mathrm{M} \mathrm{NaCl}, 10 \mathrm{mM}$ Tris, $\mathrm{pH} 8$, and $1 \mathrm{mM}$ EDTA, pH 8] containing labeled cRNA probes $\left(10^{7}\right.$ $\mathrm{cpm} / \mathrm{mL}$ ) and sealed with liquid DPX mountant for $16-20$ at $65^{\circ} \mathrm{C}$. After hybridization, sections were incubated with RNase A $(20 \mu \mathrm{g} / \mathrm{mL})$ for $30 \mathrm{~min}$ at $37^{\circ} \mathrm{C}$, followed by washes of decreasing salinity (2-0.5 $\times$ saline-sodium citrate (SSC) buffer with $10 \mathrm{mM}$ DTT) at RT, and a 30 min wash in $0.1 \times$ SSC with 10 mM DTT at $70^{\circ} \mathrm{C}$. Tissue sections were cooled briefly to RT in $0.1 \times \mathrm{SSC}$, dehydrated, dried, and apposed to $\beta$-max film (Kodak) along with ${ }^{14} \mathrm{C}$ standards of known radioactivity in light-tight cassettes for 1-2 days.

\section{Quantitative autoradiography}

Autoradiograms were quantified using a computerbased image analysis system (MCID, Imaging Research, St. Catherine, Ontario, Canada) using cali brated standards of reference. A calibration curve of optical density against radioligand concentration was constructed using ${ }^{14} \mathrm{C}$ brain paste standards of known radioactivity. Optical densities in discrete regions of the autoradiogram were measured, and values of radioactivity $(\mathrm{dpm} / \mathrm{mg}$ tissue) were calculated by interpolation from the calibration curve. Regions to be measured were determined using transparencies containing outlines of cortical layers and white matter in ACx and thalamic subnuclei in the MG constructed from adjacent Nissl-stained sections (cresyl violet). In P10 and older animals, 


\section{NR2A}

antisense
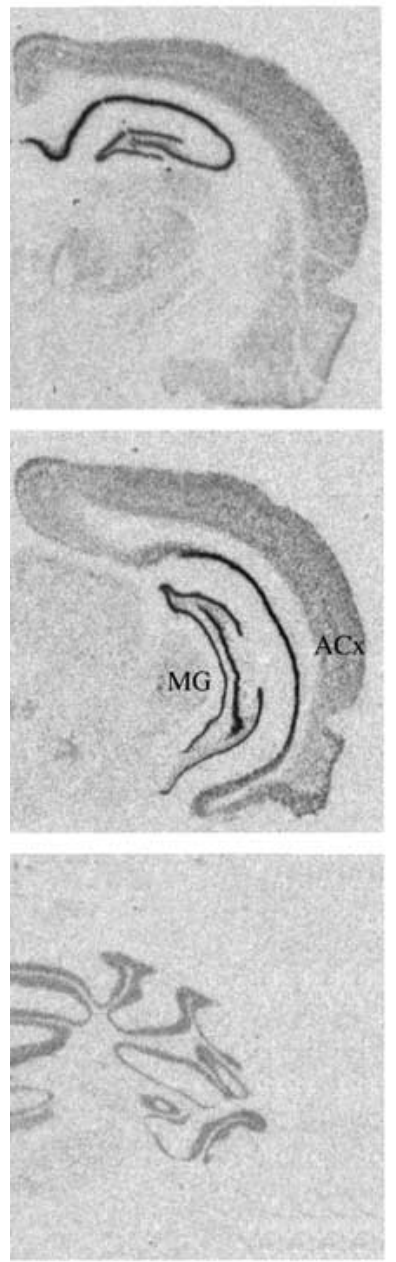

FIG. 1. Coronal brain sections from adult rat processed for NR2A and NR2B mRNA with in situ hybridization. Hybridization for antisense and sense probes is shown for adjacent sections containing auditory cortex (ACX) and the medial geniculate nucleus of the thal-
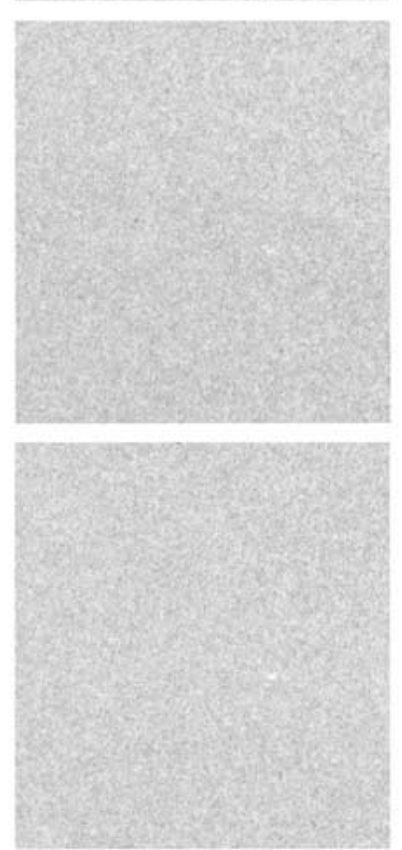

\section{NR2B}
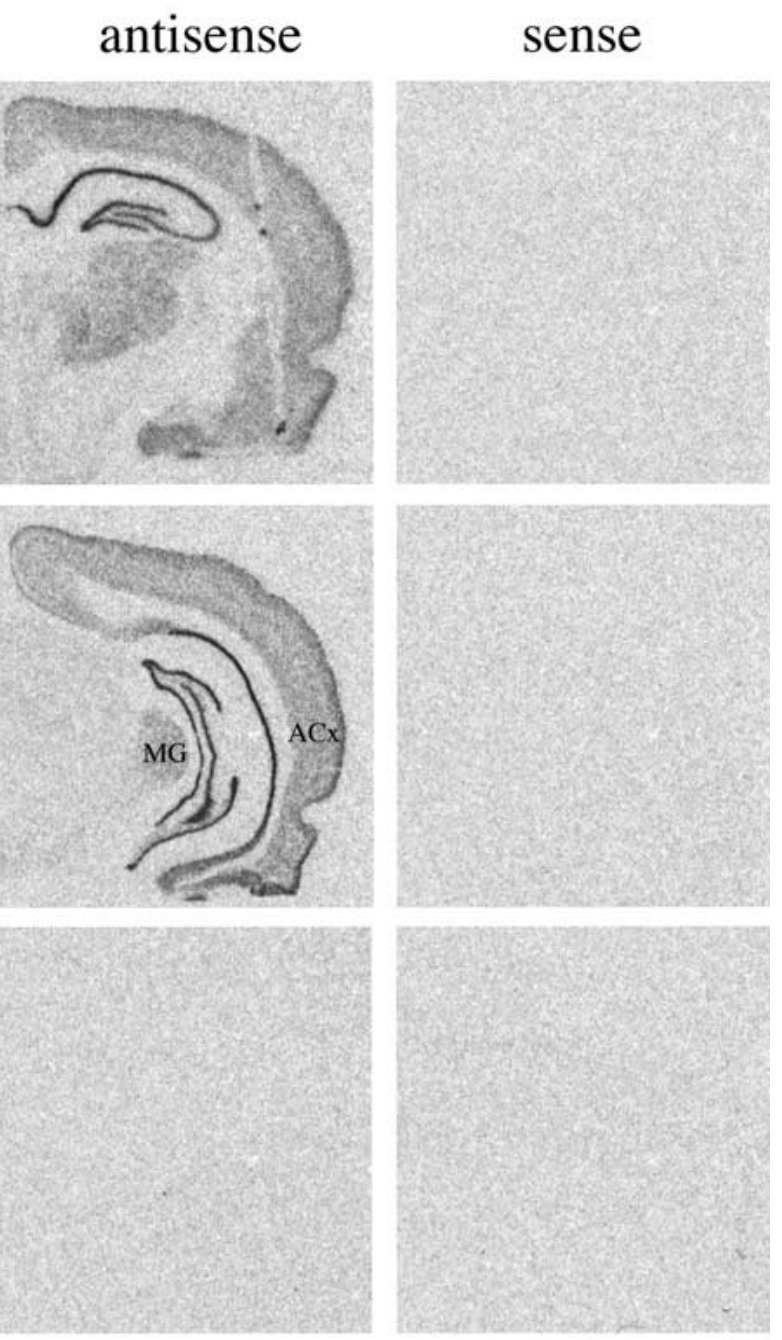

amus (MG) (middle row of sections), as well as for adjacent sections at more rostral (top row, containing dorsal hippocampus and ventrobasal thalamus) and caudal (bottom row, containing cerebellum) levels of the brain. Scale bar $=1 \mathrm{~mm}$.

the mean. Statistical comparisons were repeated measures ANOVAs, except where noted. F-statistics $(F)$ and degrees of freedom $(d f)$ are reported for age and layer effects.

\section{RESULTS}

NR2A and NR2B probes were developed from noncoding regions of cDNAs (280 and $319 \mathrm{bp}$, respectively) and tested on adult brain tissue. Full brain maps were generated which gave data similar to those previously reported for expression of these mRNAs (Monyer et al. 1994; Zhong et al. 1995; Wenzel et al. 1997). Figure 1 shows sections demonstrating NR2A 


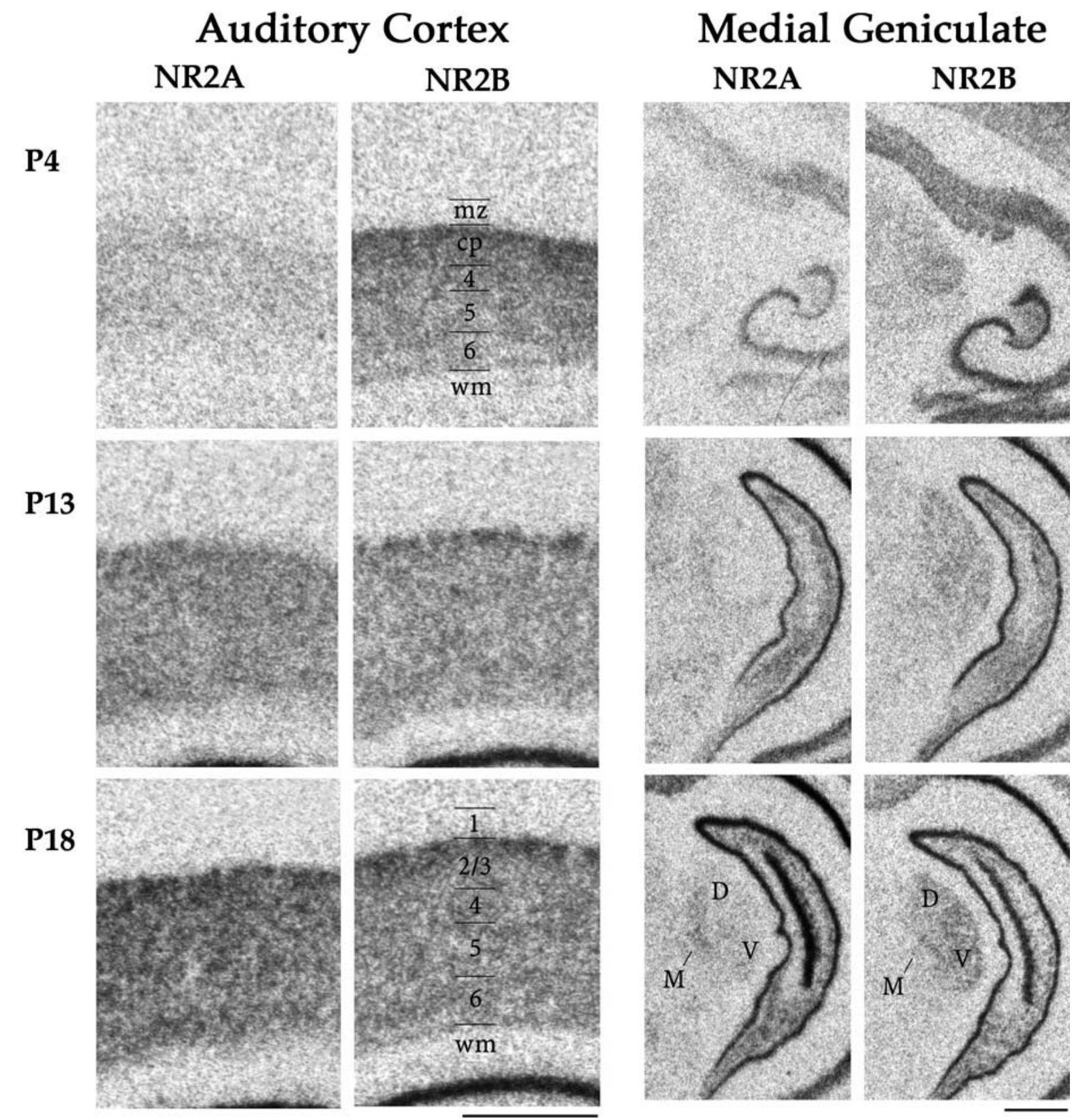

FIG. 2. Developmental sequence of expression of NR2A and NR2B mRNA in auditory forebrain. ACx and MG expression of NR2A and NR2B mRNA is shown for ages P4, P13, and P18. Cortical layers $1-6$ and white matter (wm) are indicated (P18, NR2B section),

and NR2B mRNA expression in ACx and MG (middle row) as well as expression at more rostral and caudal levels of the brain. Similar to previous reports, in the cerebellum there was strong expression of NR2A mRNA but an absence of NR2B mRNA (Fig. 1, bottom row). For ACx, layer 1, which exhibited no radioactive label, was included in quantification but excluded from statistical analysis to avoid obscuring more subtle laminar differences. as well as marginal zone (mz), cortical plate (cp), and layers 4-6 at $\mathrm{P} 4$. For MG, dorsal (D), ventral (V), and medial (M) subdivisions are indicated (P18 sections). Scale bars $=1 \mathrm{~mm}$.

NR2A and NR2B mRNA levels in auditory cortex

Cortical NR2A mRNA levels changed significantly with age (ANOVA, $p<0.01, F=5.768, d f=5$ ). Figure 2 shows the level of expression of NR2A mRNA in representative autoradiograms at $\mathrm{P} 4, \mathrm{P} 13$, and $\mathrm{P} 18$. Expression was very weak at $\mathrm{P} 4$ but became progressively stronger at $\mathrm{P} 13$ and P18. The quantified level of mRNA expression is shown in Figure 3 for 


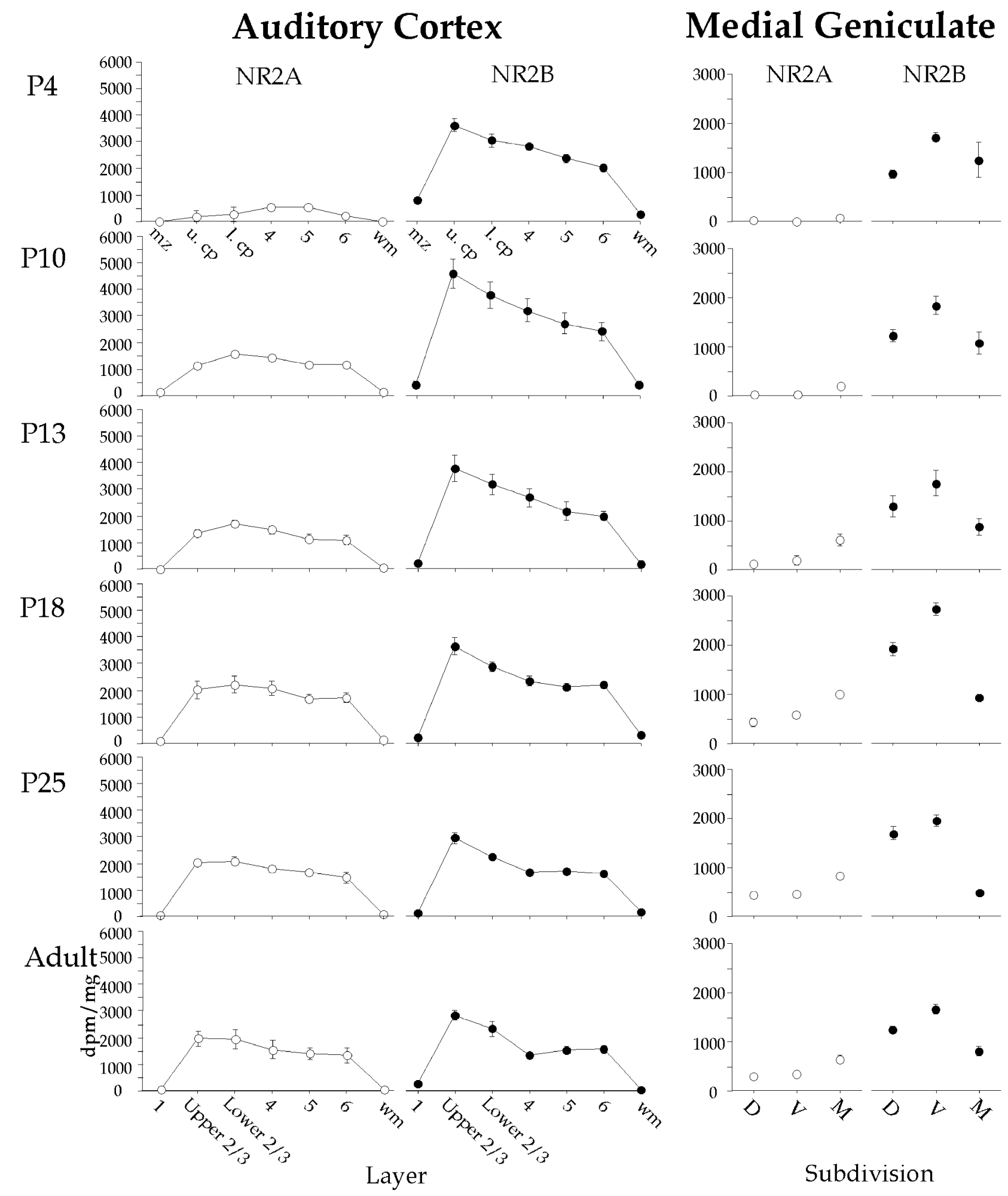

FIG. 3. Average NR2A and NR2B mRNA levels in ACx layers and MG subdivisions over development ( $\mathrm{P} 4$ to adult). Optical density measures were converted to radioactivity $(\mathrm{dpm} / \mathrm{mg})$ to indicate levels of NR2A (open circles) and NR2B (filled circles) mRNA. Abbreviations as in Fig. 2. Note that both cortical plate and layer $2 / 3$ are divided into upper and lower divisions. Variability expressed as \pm 1 SE of the mean. ANOVA $F$-statistics $(F)$ are as follows (degrees of freedom $=4$ in $\mathrm{ACx}$ and 2 in MG): ACx NR2A-P10, $F=17.567 ; \mathrm{P} 13, F=22.990 ; \mathrm{P} 18, F$ $=5.915, ; \mathrm{P} 25, F=7.365 ;$ adult, $F=10.097$. ACx NR2B-P4, $F=$ 18.762; $\mathrm{P} 10, F=46.754 ; \mathrm{P} 13, F=24.978 ; \mathrm{P} 18, F=23.413 ; \mathrm{P} 25, F=$ 33.384; adult, $F=33.253$. MG NR2A-P10, $F=46.782 ; \mathrm{P} 13, F=$ 11.746; P18, $F=28.565 ; \mathrm{P} 25, F=30.384 ;$ adult, $F=22.230$. MG NR2B-P10, $F=13.075 ; \mathrm{P} 13, F=105.504 ; \mathrm{P} 18, F=84.640 ; \mathrm{P} 25, F=$ 64.709; adult, $F=16.078$. 
all ages. Figure 3 also shows that mRNA expression peaked at P18 before declining to adult levels (data at each age averaged across layers). In addition to age-related changes, we also found laminar differences. Expression across cortical layers differed significantly at all ages after P4 (ANOVA, $p<0.01$ ). Post hoc analyses showed that superficial layers (combined layers 2/3) generally had greater NR2A mRNA expression than deep layers (combined layers 5 and 6) (paired $t$-test, $p<0.05$ at all ages except P18).

Cortical levels of NR2B mRNA also changed with age (Figs. 1-3; ANOVA, $p<0.05, F=3.306, d f=5$ ). Unlike NR2A, however, NR2B mRNA expression started high at $\mathrm{P} 4$, increased slightly at $\mathrm{P} 10$, and then decreased steadily to adult levels (data at each age averaged across layers). In addition to age-related changes, levels of mRNA expression differed across cortical layers (ANOVA, $p<0.01$ ). The highest expression at any age appeared to be in upper layer 2/3 (Figs. 1-3), and post hoc analyses confirmed generally greater expression in superficial vs. deep layers (paired $t$-test, $p<0.01$ at all ages except $\mathrm{P} 4$, $p>0.05)$.

\section{NR2A and NR2B mRNA levels in the medial geniculate}

Thalamic mRNA expression was generally weaker than cortical expression for both NR2A and NR2B, but significant changes occurred with age and across MG subdivisions (Figs. 1-3). Expression of NR2A mRNA in the MG changed significantly with age (ANOVA, $p<0.001, F=19.598, d f=5$ ), starting with little or no expression at $\mathrm{P} 4$ and increasing to a peak at P18 before decreasing to adult levels (data averaged across subdivisions). Further, at each age after $\mathrm{P} 4$ there were significant differences in expression among MG subdivisions (ANOVA, $p<0.01$ ). Figures 1-3 suggest preferential labeling of MGm, and this was confirmed in post hoc analyses (pairwise paired $t$-tests, $p<0.05$ ).

NR2B mRNA levels in the MG also changed with age (ANOVA, $p<0.05, F=3.781, d f=5$ ). Averaging across subdivisions, there was moderate mRNA expression at $\mathrm{P} 4$ that increased to a peak at P18 before decreasing to adult levels. Further, at each age after $\mathrm{P} 4$ there were significant differences in mRNA expression among MG subdivisions (ANOVA, $p<0.01$ ). Figures 1-3 show very weak expression in MGm, stronger expression in MGd, and still stronger expression in MGv. Post hoc comparison of MGv and MGm levels showed significant differences after P4 (paired $t$-tests, $p<0.05$ ).

\section{DISCUSSION}

We have determined changes in expression patterns for NR2A and NR2B mRNA in the rat auditory forebrain from $\mathrm{P} 4$ to adulthood. In the ACx, NR2A mRNA expression is initially very weak but increases rapidly to a peak at P18 before declining slightly to adult levels. NR2B mRNA levels are initially high and remain high, though they decline slightly in the adult. For both subunits, mRNA expression tends to be higher in superficial layers of the cortex (except for layer 1, which has no expression) than in deep layers. In the MG, expression for both subunits is generally weaker than in ACx. NR2A mRNA expression is initially very low, whereas NR2B mRNA expression is initially moderate. Both levels increase over time and peak at P18 before declining to adult levels. Among MG subdivisions, NR2A mRNA expression occurs preferentially in MGm, whereas NR2B mRNA expression is strongest in MGv.

General features and implications of NR2A and NR2B mRNA distributions

NMDARs consist of the NR1 subunit in combination with one or more NR2 subunits (NR2A-D) (Monyer et al. 1994; Vicini et al. 1998). The NR2A and NR2B subunits, in particular, have been shown to influence functional properties of the NMDAR that may underlie cortical plasticity (Monyer et al. 1994; Flint et al. 1997; Vicini et al. 1998). Thus, we have focused on the distribution of NR2A and NR2B mRNA in the auditory forebrain to understand variations in functional properties of the NMDAR during development. While many studies have described NR2A and NR2B mRNA and protein levels, these studies generally have not focused on specific brain regions but rather on overall changes in expression (Watanabe et al. 1993; Monyer et al. 1994; Zhong et al. 1995; Wenzel et al. 1997). Nonetheless, the developmental changes in NR2A and NR2B expression levels are similar to those reported in the present study. That is, NR2A expression is generally low at birth but increases over several weeks, whereas NR2B is high at birth and remains relatively high; both tend to peak around P10-P21 and then decline slightly through adulthood. Differences among cortical areas, including laminar differences, and among thalamic nuclei are illustrated but generally are not examined closely. A few studies have focused on individual areas, visual cortex in particular (see below). In comparing these reports, it is clear that laminar and areal differences in expression patterns exist and may reflect functional differences among brain regions. 
Similarly, differences in expression patterns among ACx layers and MG subdivisions may reflect functional differences, assuming corresponding changes in protein function (Monyer et al. 1994; Sheng et al. 1994; Zhong et al. 1995; Flint et al. 1997). Note, however, that mRNA patterns do not always correspond with protein levels (Wenzel et al. 1997; Cao et al. 2000b). While changes in mRNA levels are better quantified using other techniques (which, however, do not provide detailed information on spatial distributions), studies on other cortical areas demonstrate that in situ hybridization data can, in general, support data obtained with more quantitative methods (Sheng et al. 1994; Zhong et al. 1995). In ACx, all layers except layer 1 show expression, with the highest levels in layers $2 / 3$. This finding is generally consistent with studies of adult and developing cortex that show high levels of NMDAR mRNA and protein in superficial layers (Monaghan and Cotman 1985; Watanabe et al. 1993; Gordon et al. 1997), but note that studies directed at visual cortex have obtained somewhat different quantitative laminar profiles (Nase et al. 1999; Cao et al. 2000b). Layers 2/3 of primary ACx receives inputs from and project to other cortical regions (Wallace et al. 1991; Winer 1992 ), whereas layers $3 / 4$ receive thalamic input from the primary auditory relay in MGv (Mitani and Shimokouchi 1985; Winer 1992; Romanski and LeDoux 1993). The deeper layers $5 / 6$ receive inputs from some nonprimary thalamic nuclei, including MGm, and project to cortical and subcortical targets (Jacobson and Trojanowski 1975; Caviness and Frost 1980; Kelly and Wong 1981; Linke and Schwegler 2000). Physiological studies have demonstrated significant NMDAR-mediated EPSPs in layers 2-4 of ACx in young and juvenile rats ( P3-P30; Metherate and Ashe 1994, 1995; Aramakis and Metherate 1998). Thus, the ACx layers with strongest NR2A and NR2B mRNA expression are important for thalamic inputs and intracortical connections and display strong NMDAR EPSPs.

In the MG, expression levels for NR2A and NR2B are generally lower than for ACx, but physiological studies have demonstrated NMDAR-mediated EPSPs occur nonetheless (Hu et al. 1994; Bartlett and Smith 1999). Both MGd and MGv neurons have NMDAR EPSPs in response to stimulation of inputs from either the inferior colliculus (the main ascending auditory input) or ACx. In one study (Hu et al. 1994), NMDAR EPSPs were more prominent in MGd than in MGv. In another study (Bartlett and Smith 1999), NMDAR EPSPs in MGd and MGv were of variable amplitude, with little difference seen between subdivisions. Similar experiments have not been performed in MGm. The functional relevance of the relatively higher levels of NR2A mRNA in MGm and
NR2B mRNA in MGv seen in the present study remains to be determined.

\section{Implications for development of synaptic function}

The physiological studies described in the previous section demonstrate that NMDAR-mediated EPSPs are prominent in the ACx and MG. However, beyond indicating the general involvement of NMDARs, the data do not indicate how differential expression of NMDAR subunits contributes to functional differences. Studies of receptors expressed in cell lines have shown that NR1 subunits combined with NR2A subunits produce fast-decaying responses to glutamate, whereas combinations of NR1 with other NR2 subunits (NR2B-D) produce longer-decaying responses (Monyer et al. 1994; Vicini et al. 1998). Since it has been reported that NR2B mRNA levels change very little from their initially high levels while NR2A mRNA levels markedly increase, it is likely that a progressive alteration in subunit composition occurs during development, changing NMDAR kinetics and function. While the present study does not indicate whether NR2A and NR2B subunits are found in the same neurons, this is often the case (Sheng et al. 1994; Flint et al. 1997; Luo et al. 1997; Cao et al. 2000b). Furthermore, it has been reported that the addition of NR2A subunits to neurons already containing NR2B results in properties intermediate to those characterized in receptors containing only NR2A or NR2B, e.g., intermediate current duration (Flint et al. 1997; Vicini et al. 1998) and sensitivity to NR2B antagonists (Brimecombe et al. 1997). Thus, early postnatal ACx with high levels of NR2B but low levels of NR2A should have long-duration NMDAR EPSPs, but durations should decrease proportionally with increased NR2A expression. An examination of the duration of glutamate-mediated EPSPs in ACx layer 3/4 showed a 75\% decrease between the ages of P8 and P26, with changes occurring most rapidly during the second and third postnatal weeks and more slowly during the fourth week (Aramakis et al. 2000). Intrinsic membrane properties (e.g., input resistance and time constant) also change rapidly during the second and third postnatal weeks (Metherate and Aramakis 1999) and could contribute to the decrease of EPSP duration. However, pharmacological manipulations which dramatically increase EPSP duration do not alter intrinsic membrane properties (Aramakis et al. 2000) which demonstrates the potential involvement of other factors as well.

\section{Implications for ACx critical periods}

In considering the involvement of NMDARs in ACx critical periods it is instructive to examine the more extensive data from other sensory cortices. Early in development, neurons have low levels of NR2A 
subunits, long-duration EPSCs, and high efficacy for inducing synaptic plasticity (long-term potentiation, LTP); however, later in development, increased NR2A subunit expression is associated with fasterdecaying EPSCs and decreased LTP efficacy (Carmignoto and Vicini 1992; Crair and Malenka 1995; Flint et al. 1997; Roberts and Ramoa 1999; Barth and Malenka 2001; Philpot et al. 2001). Research on the role of NMDARs in critical periods has focused heavily on the visual cortex, due to well-characterized manipulations of critical period (ocular dominance) plasticity. For example, prolonging the critical period for ocular dominance plasticity by dark-rearing delays the expression of NR2A subunits and the shortening of EPSCs. and prolongs the period of enhanced LTP (Carmignoto and Vicini 1992; Kirkwood et al. 1995; Nase et al. 1999; Philpot et al. 2001). Subsequent exposure to light induces expression of NR2A subunits within hours (Quinlan et al. 1999; Philpot et al. 2001). These findings imply a close connection between sensory experience, NR2A expression, EPSC kinetics, and developmental plasticity. Some have proposed that the ratio of subunits may reflect phases of development, with high NR2B/NR2A ratios being associated with heightened synaptic plasticity and low ratios signaling decreased plasticity (Quinlan et al. 1999; Roberts and Ramoa 1999).

The present study indicates that NR2 mRNA levels in ACx change dramatically during postnatal development. Given the evidence relating NR2 subunits to plasticity in visual cortex (above), the present data suggest that an ACx critical period may occur during the first three weeks. Since the onset of hearing in rats is early in the second week (see Introduction), the immediately subsequent time could be most important for auditory experience-driven plasticity. Notably, the largest increase in NR2A levels is seen at P10, approximately one day after the onset of hearing. It may be relevant that recent studies from our group indicate that week 2 is a "critical period" for the effects of exogenous nicotine on glutamatergic synaptic transmission in ACx, and that the nicotineinduced effects are selective for EPSPs mediated by NMDARs (Aramakis and Metherate 1998; Aramakis et al. 2000). Further studies will be required to determine the nature of this critical period and the specific involvement of NMDAR subunits.

\section{ACKNOWLEDGMENTS}

This work was supported by the National Institutes of Health (DA12929 and DA10612) and the California Tobacco-Related Disease Research Program (8RT-0059). The authors thank Ronit Lazar and Dora Castaneda for technical support.

\section{REFERENCES}

Aramakis VB, Hsieh CY, Leslie FM, Metherate R. A critical period for nicotine-induced disruption of synaptic development in rat auditory cortex. J. Neurosci. 20:6106-6116, 2000.

Aramakis VB, Metherate R. Nicotine selectively enhances NMDA receptor-mediated synaptic transmission during postnatal development in sensory neocortex. J. Neurosci. 18:8485-8495, 1998.

Barth AL, MaLenka RC. NMDAR EPSC kinetics do not regulate the critical period for LTP at thalamocortical synapses. Nat. Neurosci. 4:235-236, 2001.

Bartlett EL, Smith PH. Anatomic, intrinsic, and synaptic properties of dorsal and Ventral division neurons in rat medial geniculate body. J. Neurophysiol. 81:1999-2016, 1999.

Berardi N, Pizzorusso T, Maffe L. Critical periods during sensory development. Curr. Opin. Neurobiol. 10:138-145, 2000.

Blatchley BJ, Cooper WA, Coleman JR. Development of auditory brainstem response to tone pip stimuli in the rat. Brain Res. 429:75-84, 1987.

Brimecombe JC, Boeckman FA, Aizenman E. Functional consequences of NR2 subunit composition in single recombinant $\mathrm{N}$-methyl-D-aspartate receptors. Proc. Natl. Acad. Sci. USA 94:11019-11024, 1997.

Cao Z, Lickey ME, Liu L Kirk E, Gordon B. Postnatal development of NR1, NR2A and NR2B immunoreactivity in the visual cortex of the rat. Brain Res. 859:26-37, 2000a.

CAO Z, Liu L, Lickey M, Gordon B. Development of NR1, NR2A and NR2B mRNA NR1 immunoreactive cells of rat visual cortex. Brain Res. 868:296-305, 2000b.

Carmignoto G, Vicini S. Activity-dependent decrease in NMDA receptor responses during development of the visual cortex. Science 258:1007-1011, 1992.

CAVIness VS Jr, Frost DO. Tangential organization of thalamic projections to the neocortex in the mouse. J. Comp. Neurol. 194:335-367, 1980.

Clerici WJ, Coleman JR. Postnatal cytoarchitecture of the rat medial geniculate body. J. Comp. Neurol. 399:110-124, 1998.

Crair MC, Malenka RC. A critical period for long-term potentiation at thalamocortical synapses. Nature 375:325-328, 1995.

Crowley DE, Hepp-Reymond MC. Development of cochlear function in the ear of the infant rat. J. Comp. Physiol. Psychol. 62: 427-432, 1966.

Cruikshank SJ, Killackey HP, Metherate R. Parvalbumin and calbindin are differentially distributed within primary and secondary subregions of the mouse auditory forebrain. Neuroscience 105:553-569, 2001.

Flint AC, Maisch US, Weishaupt JH, Kriegstein AR, Monyer H. NR2A subunit expression shortens NMDA receptor synaptic currents in developing neocortex. J. Neurosci. 17:2469-2476, 1997.

Fox K, Henley J, Isaac J. Experience-dependent development of NMDA receptor transmission. Nat. Neurosci. 2:297-299, 1999.

Gordon B, Kinch G, Kato N, Keele C, Lissman T, Fu LN. Development of MK-801, kainate, AMPA, and muscimol binding sites and the effect of dark rearing in rat visual cortex. J. Comp. Neurol, 383:73-81, 1997.

Hu B, Senatorov V, Mooney D. Lemniscal and non-lemniscal synaptic transmission in rat auditory thalamus. J. Physiol. 479:217231, 1994.

Ignacio MP, Kimm EJ, Kageyama GH, Yu J, Robertson RT. Postnatal migration of neurons and formation of laminae in rat cerebral cortex. Anat. Embryol. (Berl.) 191:89-100, 1995.

IwASA H, Potsic WP. Maturational change of early, middle, and late components of the auditory evoked responses in rats. Otolaryngol. Head. Neck. Surg. 90:95-102, 1982. 
Jacobson S, Trojanowski JQ. Corticothalamic neurons and thalamocortical terminal fields: an investigation in rat using horseradish paeroxidase and autoradiography. Brain Res. 85:385-401, 1975.

Kelly JP, Wong D. Laminar connections of the cat's auditory cortex. Brain Res. 212:1-15, 1981.

KirkwoOd A, LeE HK, BeAR MF. Co-regulation of long-term potentiation and experience-dependent synaptic plasticity in visual cortex by age and experience. Nature 375:328-331, 1995.

LiNKe R, SCHWEgLER H. Convergent and complementary projections of the caudal paralaminar thalamic nuclei to rat temporal and insular cortex. Cereab. Cortex 10:753-771, 2000.

LuO J, Wang Y, Yasuda RP, Dunah AW, Wolfe BB. The majority of $\mathrm{N}$-methyl-D-aspartate receptor complexes in adult rat cerebral cortex contain at least three different subunits (NR1/NR2A/ NR2B). Mol. Pharmacol. 51:79-86, 1997.

Metherate R, Aramakis VB. Intrinsic electrophysiology of neurons in thalamorecipient layers of developing rat auditory cortex. Dev. Brain Res. 115:131-144, 1999.

Metherate R, Ashe JH. Facilitation of an NMDA receptor-mediated EPSP by paired-pulse stimulation in rat neocortex via depression of GABAergic IPSPs. J. Physiol. 481:331-348, 1994.

Metherate R, Ashe JH. GABAergic suppression prevents the appearance and subsequent fatigue of an NMDA receptor-mediated potential in neocortex. Brain Res. 699:221-230, 1995.

Miao H, Liu C, Bishop C, Gong ZH, Nordberg A, Zhang X. Nicotine exposure during a critical period of development leads to persistent changes in nicotinic acetylcholine receptors of adult rat brain. J. Neurochem. 70:752-762, 1998.

Mitani A, Shimokouchi M. Neuronal connections in the primary auditory cortex: an electrophysiological study in the cat. J. Comp. Neurol. 235:417-429, 1985.

Monaghan DT, Cotman CW. Distribution of $N$-methyl-D-aspartatesensitive L-[3H]glutamate-binding sites in rat brain. J. Neurosci. 5:2909-2919, 1985.

Monyer H, Burnashev N, Laurie DJ, Sakmann B, Seeburg PH. Developmental and regional expression in the rat brain and functional properties of four NMDA receptors. Neuron 12:529$540,1994$.

Nase G, Weishaupt J, Stern P, Singer W, Monyer H. Genetic and epigenetic regulation of NMDA receptor expression in the rat visual cortex. Eur. J. Neurosci. 11:4320-4326, 1999.

Philpot BD, Sekhar AK, Shouval HZ, Bear MF. Visual experience and deprivation bidirectionally modify the composition and function of NMDA receptors in visual cortex. Neuron 29:157169, 2001.
Quinlan EM, Philpot BD, Huganir RL, Bear MF. Rapid, experience-dependent expression of synaptic NMDA receptors in visual cortex in vivo. Nat. Neurosci. 2:352-357, 1999.

Roberts EB, Ramoa AS. Enhanced NR2A subunit expression and decreased NMDA receptor decay time at the onset of ocular dominance plasticity in the ferret. J. Neurophysiol. 81:25872591, 1999.

Robertson RT, Mostamand F, Kageyama GH, Gallardo KA, Yu J. Primary auditory cortex in the rat: transient expression of acetylcholinesterase activity in developing geniculocortical projections. Dev. Brain Res. 58:81-95, 1991.

RoMANSki LM, LeDoux JE. Organization of rodent auditory cortex: anterograde transport of PHA-L from MGv to temporal neocortex. Cereb. Cortex 3:499-514, 1993.

Sheng M, Cummings J, Roaldan LA, Jan YN, Jan LY. Changing subunit composition of heteromeric NMDA receptors during development of rat cortex. Nature 368:144-147, 1994.

Simmons DM, Arriza JL, Swanson LW. A complete protocol for in situ hybridization of messenger RNA in brain and other tissues with radiolabeled single-stranded RNA probes. J. Histotechnol. 12:169-181, 1989.

Vicini S, Wang JF, Li JH, Zhu WJ, Wang YH, Luo JH, Wolfe BB, GraYson DR. Functional and pharmacological differences between recombinant $\mathrm{N}$-methyl-D-aspartate receptors. J. Neurophysiol. 79:555-566, 1998.

WaLlace MN, Kitzes LM, Jones EG. Intrinsic inter- and intralaminar connections and their relationship to the tonotopic map in cat primary auditory cortex. Exp. Brain Res. 86:527-544, 1991.

Watanabe M, Inoue Y, Sakimura K, Mishina M. Distinct distributions of five $N$-methyl-D-aspartate receptor channel subunit mRNAs in the forebrain. J. Comp. Neurol. 338:377-390, 1993.

Wenzel A, Fritschy JM, Mohler H, Benke D. NMDA receptor heterogeneity during postnatal development of the rat brain: differential expression of the NR2A, NR2B, and NR2C subunit proteins. J. Neurochem. 68:469-478, 1997.

Winer JA (1992) The functional architecture of the medial geniculate body and the primary auditory Cortex. In: Webster BB and popper AN (eds) The Mammalian Auditory Pathway: Neuroanatomy. New York, Springer-Verlag. pp 222-409.

Winzer-Serhan UH, Broide RS, Chen Y, Leslie FM. Highly sensitive radioactive in situ hybridization using full length hydrolyzed riboprobes to detect alpha 2 adrenoceptor subtype mRNAs in adult and developing rat brain. Brain Res. Brain Res. Protoc. 3:229-241, 1999.

Zhong J, Carrozza DP, Williams K, Pritchett DB, Molinoff PB. Expression of mRNAs encoding subunits of the NMDA receptor in developing rat brain. J. Neurochem. 64:531-539, 1995. 